\title{
Interrogating Social Media in Education: The Case of Ahmadu Bello University Zaria Nigeria
}

\author{
Rasheedah Liman \\ http://dx.doi.org//10.4314/ujah.v17i1.5
}

\section{Abstract}

This paper examines the relationship between Social Media use and its educational and social impact on the undergraduate students of Ahmadu Bello University Zaria. It explores both the negative and positive dimensions of Social Media within the larger framework of New Media and higher education. The research draws on previous researches done with students, particularly in developed countries like the United States with the insight of highlighting the implications for students in Nigeria. Participatory Communication theory was used to ground the research and quantitative method is employed in order to collect data. The aim of the research is to provide an understanding of the usefulness and efficacy of Social Media in the educational enterprise in Nigeria.

\section{Introduction}

The use of technology has historically been linked to the field of higher education and the use of Social Media has continued this trend. The use of technology in education has been studied at least as far back as 1974 (Gagne, 1974) but it began to resemble the current use and format in the late 1990s, with the introduction of Microsoft Windows platform (Martinez-Aleman and Wartman, 2009). The introduction of the personal computer made computer more user-friendly and accessible. This reduced the skill required to operate a computer and is said to have "ignited the use of personal computers on college campuses" (Lehartz, 2012). The link between technology and education necessitates paying attention to how students, in this case, students of Ahmadu 
Bello University Zaria, use Social Media and how it impacts their education.

The urgency and need to better understand the potential benefits and impact of New Media technologies in higher education, is like never before, particularly in Nigeria where research indicates as having the highest Internet and Facebook users in Africa (World Statistics 2012). The credence to the need of understanding the relationship between education and New media technologies in Nigeria has also been upped by the report on Nigeria's Education Policy, which maintains in its 2013 report that "individuals in our society who do not possess the levels of skills, literacy and training essential to this new era will be effectively disenfranchised, not simply from the material rewards that accompany competent performance, but also from the chance to participate fully in the national development of Nigeria." In this light, it is important not to foreclose the possible potential benefits of both informal and formal learning through Social Media or experimentation with teaching using Social Media in the classroom.

Furthermore, web-based Social Media makes it possible to connect people who share interest and activities, across political, economic and geographical borders through instant messaging. Scholars such as LaRose (2011), Livingstone (2006), Boyd and Ellison (2006) have investigated how Social Media impact on student education in higher institution. Boyd and Ellison (2007) in their book, Social Network Sites: Definition, History and Scholarship look at, among other issues, the implication of social networking sites use in schools. They argue that social networking sites are not only beneficial to students, but they can also provide new opportunities for participatory communication among teachers and students. 
This point seems to be accurate to the extent that there are various instances where teachers and students in Ahmadu Bello University Zaria, communicate on social networking sites like Facebook about classroom activities. Similar instances can also be drawn from "Stars from the Well" a Facebook group, where students of Theatre and Performing Arts Ahmadu Bello University Zaria, post questions concerning class assignments and members of that group also have online discussion concerning any posted subject matter. Thus, in order to guide this study, two cogent questions have been drawn;

- What Social Media is in common usage by Undergraduate Students of Ahmadu Bello University?

- What are the prospects of synergizing classroom teaching with Social Media in order to create effective learning among students of Ahmadu Bello University, Zaria?

\section{Review of Literature}

The term "Social Media" and "Social Networking" is often being used interchangeably without a clear definition. In general, the term "Social Media" seems to be most often used as a broader umbrella term that includes many Web 2.0 functions, including Social Networking. The term Social Media will be used in this study to address a broader category that contains social networking sites, blogs, YouTube and Wikis. While "Social Networking" will be used to describe social networking sites used primarily as a means of communication and building community. For example a blog would be considered a Social Media application used to share a message but does not necessarily fit the description of a social networking site. 
Facebook, on the other hand, is used primarily as a communication device and to build community, so it is considered a social networking website as well as being part of the broader category of social media tools. According to Lehartz (2012:11) "social networking applications are automatically part of social media, but the inverse is not necessarily true". Having a clear understanding of these concepts ensures a proper focus on the research area. Social Networking sites have become an important part of most people's lives in terms of entertainment, information and education. Unfortunately there are very few literature on Social Networking Site use amongst students in Nigeria. This present research is therefore important because it attempts to fill the gap on SNSs literature in Nigeria.

However, Waheed (2012) did a study on teacher's usage of Internet as a teaching tool in class in Nigeria. Waheed Oluwa (2012) in his article "Assessment of Internet Uses, Practices and Barriers for Professional Development by Agricultural Science Teachers in Lagos State" carried out a study on the utilization of the Internet by agricultural science teachers in Lagos State Nigeria focusing on uses, practices, and barriers. A survey was developed based on literature and was administered to 300 agricultural science teachers in Lagos schools. Of the 275 returned survey, only 130 (47.2\%) teachers indicated that they have access and use Internet for teaching and learning activities in classrooms. The remaining teachers (144) reported that they have not used the Internet at all for the purpose of teaching and learning in the classroom. The study found that agricultural science teachers in Lagos State have not fully utilized the Internet because of barriers related to time factor, accessibility, and facilities (Waheed, 2012).

LaRose at el. (2011) in their article "Facebook Fiends: Compulsive Social Networking and Adjustment to College" 
investigates the relationship between Social Networking Sites use and academic, social and psychological adjustment in a population of first year college students in the United States. Facebook use was defined in this article as "overt, observable acts of SNS activities." This can be linked with the amount of time users spend on Social Networking Sites per day or week or the number of friends the user has accumulated over a period of time. The study points to the fact that compulsive use of Social Networking sites had a negative relationship with all academic adjustment dimensions (motivation, performance, attachment) (LaRose, 2011). Thus, compulsive use is what is potentially problematic for educational outcome rather than habitual involvement with Social Networking sites particularly, amongst first year college students in the United States.

Minocha (2009) provided a series of case studies on social media software use at English Universities, including the use of virtual world website "Second Life" and blogs by students to create group discussion, a Facebook group specifically created for first year English students, a library blog using the social bookmarking website "Delicious", a social network specifically designed for doctoral students, and blogging as a support network for trainee teachers, and the use of social photo sharing website "Flicker" as a tool for photography students. It seems doubtful that all of these innovative uses of Social Media will prove to be successful. However, with time and additional research, it will be interesting to see which of the many uses of social media in higher education listed by Minocha (2009) will prove to be successful and become part of the educational experience.

Lampe et al (2011) in their research "Student use of Facebook for Organizing Collaborative Classroom Activities" examine how undergraduate students use Facebook to engage in classroom related collaborative activities, such as arranging 
study groups and learning about course processes. The research was done in order to learn how Facebook might be used as an "informal tool that students use to organize their class room experience." Hsiu-Tin Hung et al. (2009) explored how social networking technology can be used to supplement face-to face courses as a means of enhancing student's sense of community and, to promote classroom communication practice in the context of higher education. Their study titled "Educational Use of Social networking Technology in Higher education" indicates that the majority of participants developed strong feelings of social connectedness and expressed favourable feelings regarding their learning experiences in the classes where Social Networking sites were used as a supplementary tool. The picture below illustrates how teachers can use Social networking sites as supplementary teaching tool. A survey conducted in 2011 by The Babson Survey Research Group drawing from 1000 college and University faculty members through out the United States revealed that more than 80 percent use social networking sites in some capacity (Facebook, YouTube, Wiki etc). More than half of the faculty members surveyed use Social Networking site as part of their teaching. The Babson survey notes that 30 percent use Social Networking sites to communicate with their students while more than 52 percent use online videos, blogs and Wikis during actual class time. However, the limitation of this research may be attributed to the number of colleges and Universities surveyed compared to the size and number of Universities in the United States.

It is also important to mention that there are several important educational Social Media sites, which are focused primarily for the enhancement of student's academic performance. Already, sites such as YouTube host virtual classrooms of a number of universities where video lectures from eminent professors are available free of charge. Edmodo 
is an online social learning network, which provides useful learning tools for students. The Khan Academy is another example of how Social Media can provide a free and fast way to learn about almost any subject online. The site deals with questions and answer, quizzes and online tests; there is also student feedback as part of the site. www.Academia@edu.org is also another very useful educational Social Media that provides opportunity for collaboration and learning, particularly for higher institution students or graduates who are interested in research and knowledge about current trends and issues in the academia.

In Nigeria, a new educational Social Networking site called "Kranta" debuted in March 2013. "Kranta" was established by Elara Technologies is an educational site that "affords members access to academic resource, including past questions of various examinations in Nigeria, ranging from common entrance to professional examinations for free" (Oke, 2013:19). According to the CEO of Elara Technologies, Damola Olajide, his firm decided to design the site, www.kranta.com, because of the obsession with noneducational Social Media contents by students, which is attributed to their dismal performances in examinations in recent times. He further said because "it would be virtually impossible to stop students from using smart phones or visiting social media online, the firm is launching the socioeducational portal and making learning pleasurable."

The site is loaded with Social Networking features including profiles, activity feeds, comments, and group functionality. The site also gives visitors a comprehensive assessment of one's performance in test done online with statistical analysis. It also grants users access to a large database of educational materials in various fields of learning through an aggregating search engine and makes it easy to find people who share study-related materials or establish new 
contacts. The firm's Chief Operating officer, Opeyemi Obayan, said he is extremely happy that the project has been completed. According to him, "in less than three months since we launched the site, the portal has about 3,000 registered and active users" (The Guardian, 2013: 19). While 3,000 memberships do not sound exciting compared to Social Media like Facebook with over 900 million members and counting, Kranta is very recent and is indeed a remarkable development for education in Nigeria.

However, other scholars have strongly presented their argument concerning the several negative effects the New Media have on knowledge, opinion, attitudes and the levels of violence among youth in the society. New Media, they say, is responsible for aggressive tendencies among children and young people due to the amount of excessive violence in media representations that can be found in some movies or video games. Theories like the "hypodermic needle or bullet" theory give further support to these media effect behavior. However, these theories did not account for the different responses individuals may have to the same media source. There appears to be a consensus that the media may heavily influence some vulnerable groups such as children more than others (Bryant \& Thompson, 2002; McCombs \& Shaw, 1972; McLuhan, 1964). Manohar is one of the scholars who have argued strongly about the negative effect of the New Media. According to Manohar (2010:1):

The New media is responsible for creating ideals about body images, owing to which several teenagers (especially girls) suffer from inferiority complex and resort to unhealthy practices to lose weight and get skinny... the amount of celebrity hype created by the media causes many children to make irrational demands for designer clothing, accessories and other perks of the celebrity life that they are exposed to. 
Glorification of unhealthy habits like smoking, drug abuse, unprotected sex and alcohol can encourage these habits in teenagers, which can permanently scar their lives.

There are also several privacy and safety concerns on Social Media that have not yet been addressed in education. The most frequently raised issue is with the material posted on social networking sites. This issue involves students posting materials deemed inappropriate, which can include violation of privacy (nude pictures, unauthorized information, character defamation etc). Indeed, the posting of these types of materials appears to be frequent. There is certainly no shortage of cases involving the misuse of Social Media reported in the traditional media all over the world, including Nigeria.

\section{Methodology}

The Ahmadu Bello University (A.B.U) has 12 Faculties and 78 Departments excluding research centers and institutes. A.B.U is one of the largest providers of higher education in Nigeria. As at the 2012/2013 academic session, it has 30,657 registered undergraduate students only, with 9,540 female students and 21,117 male students (Management Information System, (MIS) Unit A.B.U Zaria, 2013). Lenartz (2012:53) described a sample as a subset of the population. For reasons of time and economy, it is often not feasible to study an entire population, thus the researcher makes use of the simple random sampling for this research.

In using the Simple Random Sample (SRS), the sample population is given an equal probability chance. The accuracy of the data collected using simple random sampling can easily be checked through the variance in the overall population. "The objective is to take a sample from the population, measure some characteristics on each of the sampled units, 
and use this information to estimate (infer) the characteristics in the entire population (Garton, 2013:3).

There are a number of reasons for limiting the population and sample to Ahmadu Bello University undergraduates. A.B.U students are more readily accessible and they constitute a large enough population. The researcher chose to limit it, rather than include students from other institutions because generalization about the data could more easily be done. The sample would be limited to undergraduates because this also limits the age range of respondents to young adults. More so, there is a strong correlation between age and use of social networking sites (Harris, 2008, Lenartz, 2012, Ellison, 2011). Five hundred (500) copies of questionnaire were administered randomly to undergraduate students in 10 faculties of the Ahmadu Bello University Main Campus. A total number of 400 copies were retrieved and analysed.

Descriptive statistics is used to analyse and summarise the data and responses gathered from the questionnaire using graphical formats and tables. The questionnaire was divided into four sections. A basic demographic section, which collected information about respondents' age, gender, year in school, Department, among other things; a section, which asked questions related to respondents' time spent using the Internet and Social Media for a variety of purposes; a third section was for those respondents with Social Networking accounts. The fourth section focuses on Social Media and education, including academic interaction with fellow students and lecturers.

Over the course of thirty-two (32) days in February and March 2013, 500 copies of the questionnaire were distributed and a total number of 400 were completed and returned by undergraduate students of Ahmadu Bello University Zaria. After the collection period, data were coded 
and checked for error before being imported into SPSS, a statistical software program. Descriptive statistics was used to summarize the responses and the information was presented as a numeric total displaying a summary of respondents. The results are displayed in charts and tables and a summary of the data collected was done for each graph and table.

\section{Findings and Discussion}

Data gathered from the questionnaire revealed that $83.2 \%$ of the respondents are between the ages of $18-28$. This reflects the normal age range of undergraduate students of Ahmadu Bello University who are the major focus of this study. Literature also indicates that students within these age ranges are the highest users of Social Media. The male gender constitutes $58 \%(232)$ of the respondents, while female respondent were $39.3 \%(157)$. This ratio is not surprising going by the fact that the total number of male undergraduate students in Ahmadu Bello University Zaria as at the year of this research was 21,117 compared to 9540 female students. On marital status, 93\%(N372) of the respondents were single while $4 \%$ (N16) indicated that they were married. The data revealed that 200 level (second year) students are more amongst the respondents with $30.8 \%$, followed by 400 level students with $28.8 \%$. 300 level students were $24.3 \%$ of the respondents while $9.0 \%$ were 100 level students. Respondents in this questionnaire represented most of the faculties and Departments in Ahmadu Bello University Zaria.

\section{How Ahmadu Bello University Students Use Social Networking Sites.}

The primary audience that many Social Networking sites target is young adults and the primary audience of Facebook, indeed, the site's only intended audience when it was launched in 2004 is college students. Ahmadu Bello 
University students overwhelmingly pick Facebook as their Social Networking site of choice, with 365(91.3\%) of respondents confirming an active account on the website. See graph 1 below:

Q1: Which Social Networking sites do you have accounts with? 


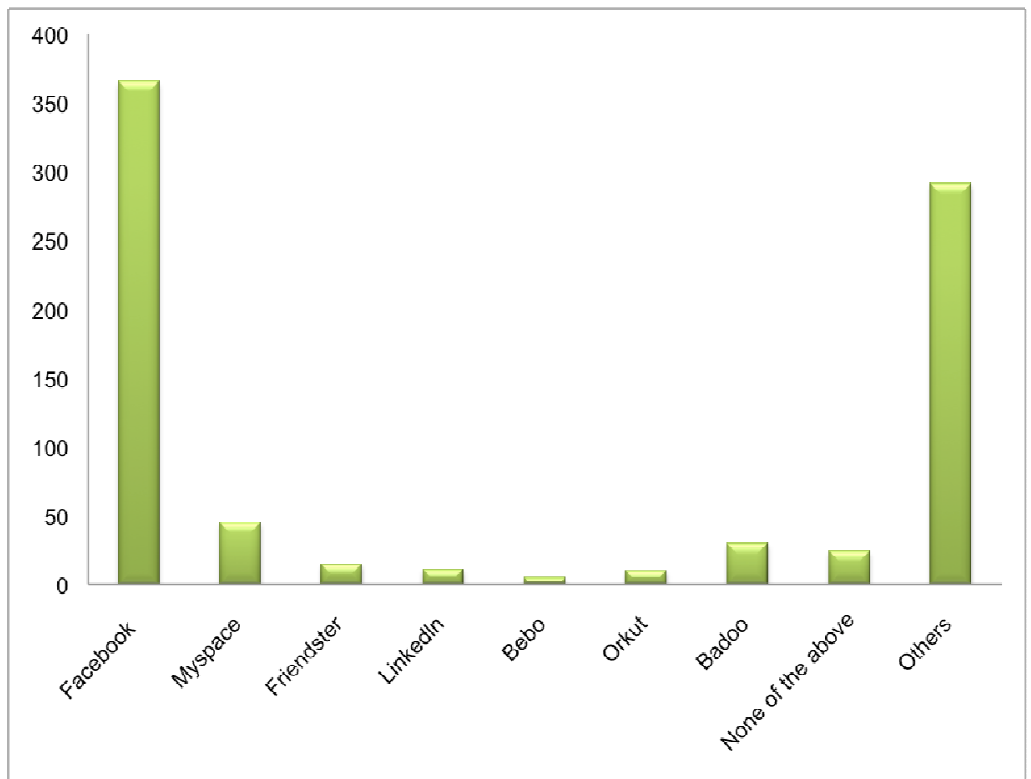

Looking specifically at how often students use social networking sites, $47 \%$ of the respondents report logging into these websites multiple times a day. When considering this percentage in relation to the respondents' gender, $41 \%$ of female respondents said they use Social Media multiple times a day, compared to $6 \%$ of male respondents. While the respondents in this research seems to take advantage of the features on social networking sites, "keeping in touch with friends" remains the top priority with $74.3 \%(\mathrm{~N} 297)$ reporting so. As might be expected from the results, $57.5 \%(\mathrm{~N} 230)$ further said keeping in touch with friends is the most important reason for using social networking sites, with academics trailing in second place at $18.8 \%(\mathrm{~N} 75), 6.3 \%(\mathrm{~N} 25)$ said making new friends and $2.5 \%(\mathrm{~N} 10)$ indicated posting/viewing pictures. While these results were consistent across gender, a slight variation can be seen across respondents' year in school, with 100 and 200 students ranking keeping in touch with friends as the most important 
reason for using the site than 300, 400 and 500 level students. See graph 2

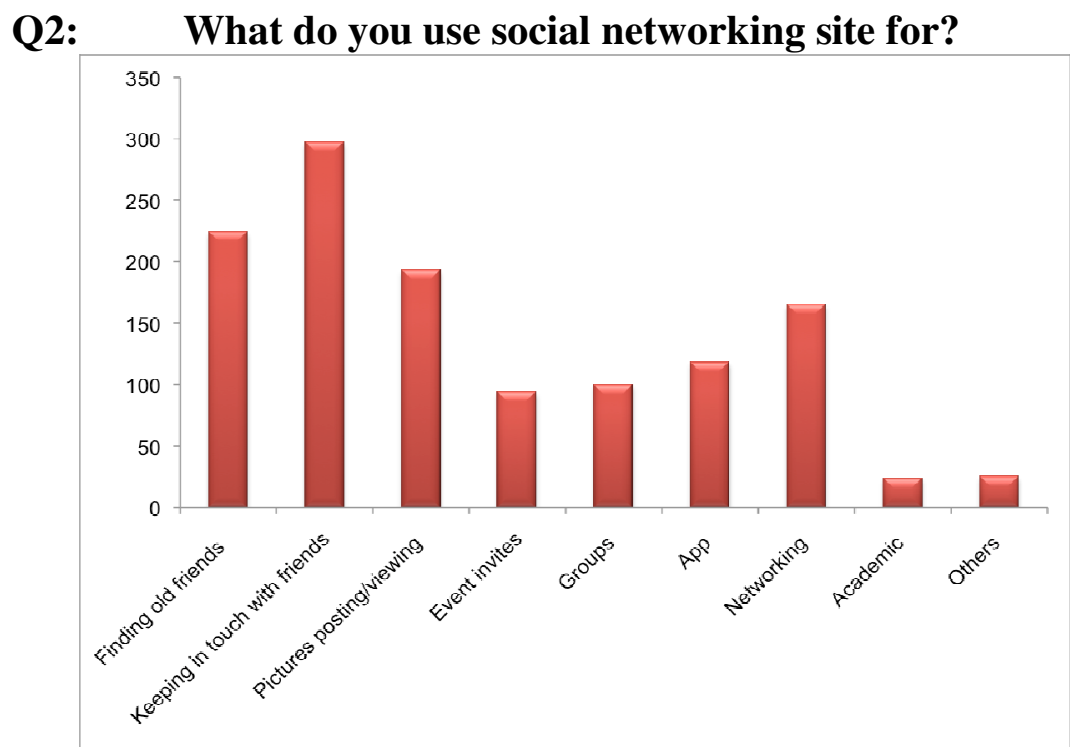

Within the University environment, one can safely say that all students need to use the Internet for a variety of educational purposes like sharing and asking academic questions with lecturers, classmates and colleagues, in addition to their personal uses. This finding also supports research question 2, which looks to the possible synergy between formal class activity and social media. If social media actually provides more access to educational material for students, then the possibility of educators actually appropriating social media tools into classroom setting is plausible. However, when asked how often they use Social Media to communicate with their lecturers, friends and classmates on academic questions, a large percentage $(71.5 \%)$ said "Never", $13.0 \%$ said "sometimes" while only $4.5 \%$ said "Frequently". 


\section{Q3: How often do you use Social Media to Communicate with your lecturers to ask academic questions?}

\begin{tabular}{|ll|r|r|r|r|}
\hline & & $\begin{array}{c}\text { Freque } \\
\text { ncy }\end{array}$ & Percent & \multicolumn{1}{|c|}{$\begin{array}{c}\text { Valid } \\
\text { Percen } \\
\text { Valid }\end{array}$} & $\begin{array}{c}\text { Cumulati } \\
\text { ve } \\
\text { Percent }\end{array}$ \\
\hline RARELY & 286 & 71.5 & 74.3 & 74.3 \\
& SOMETIMES & 52 & 7.5 & 7.8 & 82.1 \\
FREQUENTL & 17 & 4.3 & 13.5 & 95.6 \\
Y & & & & 100.0 \\
Total & 385 & 96.3 & 100.0 & \\
Missing & 15 & 3.8 & & \\
Tystem & 400 & 100.0 & & \\
\hline
\end{tabular}

In the questionnaire also, respondents were asked how much time they spend on a typical day accessing the Internet for the following purposes; Education, Communication, Entertainment and News. Use of each method scored highly but News occupied the highest percentage, communication comes in closely and Education third. Entertainment occupied the smallest amount of time according to the respondents. This is provided in the table below:

\begin{tabular}{|l|l|l|l|}
\hline $\begin{array}{l}\text { Education/Schoo } \\
\text { l work }\end{array}$ & $\begin{array}{l}\text { Communicatio } \\
\mathbf{n}\end{array}$ & $\begin{array}{l}\text { Entertainmen } \\
\mathbf{t}\end{array}$ & $\begin{array}{l}\text { New } \\
\mathbf{S}\end{array}$ \\
\hline 160 & 181 & 136 & 200 \\
\hline
\end{tabular}

When asked what are the possible challenges posed by the New Media to students' academic development? A large percentage of respondents said "students will be more distracted in classroom due to laptops and smart phone use, 
See graph 3. In this regard, $55.8 \%$ of the respondents said authorities should restrict/censor some activities on the Internet and Social Networking sites. 35.0\% disagreed while $8.0 \%$ said they "do not know".

\section{Q4: As a youth and university student, what are the possible challenges posed by the New Media to students' academic development?}

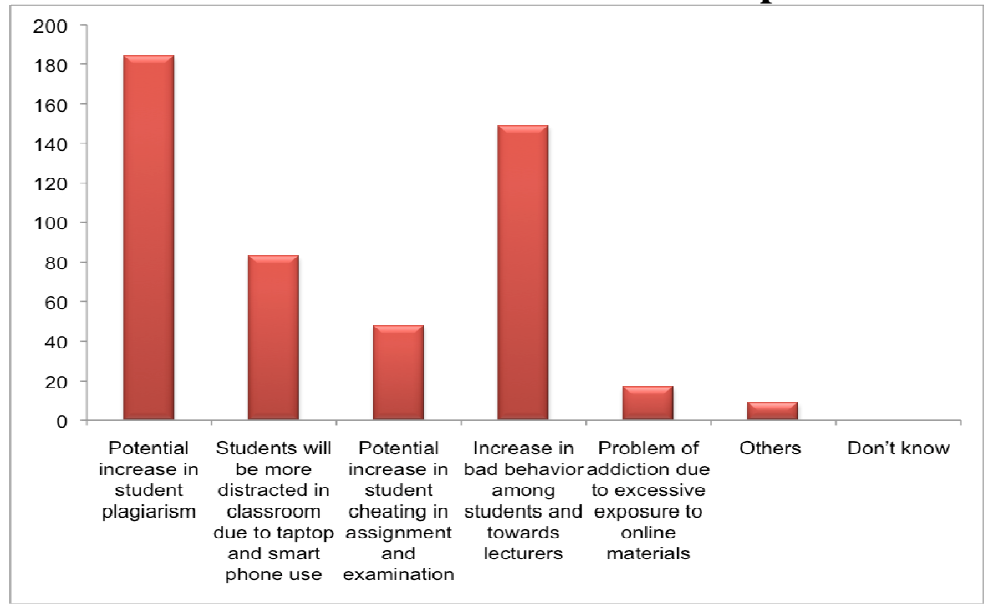

When asked where respondents reside, 66.3\% said they reside on campus while $28.3 \%$ said off campus. Staying on campus may be an indication of greater access to the Internet since Ahmadu Bello University offers students several locations to access the Internet. The campus maintains approximately 100 computers with Internet access in the University's main library coupled with the ones available in the various computer centers around the campus. The $28.3 \%$ of the respondents who indicated staying off campus may not have constant access to the Internet due to inadequate electricity and Internet connectivity but may still be able to access the Internet anywhere via electronic gadgets like smart phones using prepaid Internet services. 
Q5: Where do you currently reside?

\section{Table 25:}

\begin{tabular}{|ll|r|r|r|r|}
\hline & $\begin{array}{r}\text { Frequ } \\
\text { ency }\end{array}$ & Percent & $\begin{array}{r}\text { Valid } \\
\text { Percent }\end{array}$ & $\begin{array}{c}\text { Cumulative } \\
\text { Percent }\end{array}$ \\
\hline Valid & RESIDE & 265 & 66.3 & 70.1 & 70.1 \\
& ON & & & \\
& CAMPUS & & & & \\
& RESIDE & 113 & 28.3 & 29.9 & \\
OFF & & & & \\
CAMPUS & & & & \\
& Total & 378 & 94.5 & 100.0 & \\
Missing & System & 22 & 5.5 & & \\
Total & 400 & 100.0 & & \\
\hline
\end{tabular}

\section{Conclusion}

Students have generally been using Social Media to connect with friends. The increased use of Social Media has in turn led to the utilization of Social Media inside and outside the classroom. This is based on the real and theoretical potential benefits to institutions that can be obtained through the use of Social Media. The potential benefits include enhancing the overall college experience (Banaria, 2004), expanding educational opportunities (LaRose 2010), library services (Kaplan, 2010). In conjunction with the rapid increase in the use of Social Media by students of higher education, problems resulting from the use of Social Media are becoming increasingly apparent, such as plagiarism and the posting of inappropriate materials. This study helped to provide further clarification to these previously identified themes, by exploring what is obtainable in the context of 
Ahmadu Bello University Zaria Nigeria and its undergraduate students.

\section{Rasheedah Liman}

Department of Theatre and Performing Arts Ahmadu Bello University Zaria, Nigeria

\section{References}

Ellison, N. B et al. (2007) The Benefit of Facebook "Friends" Social Capital and College students' Use of Online social Networking sites. Journal of Computer-Mediated Communication, 12, 1143-1168.

Hsiu-Tin et al (2009) "Educational use of Social Networking Technology in Higher Education", Teaching in Higher education, Vol. 15, Issue 6, 2010.

Lampe, C et al (2011) "Student Use of Facebook for Organizing Collaborative Classroom Activities", International Journal of Computer-Supported Learning.

LaRose, R. et al (2011) "Facebook Fiends: Compulsive Social

Networking and Adjustment to College" Michigan state University, www.academia.edu

Lenartz, A.J (2012) "All My Rowdy "Friends: The Use of

Social media in Higher Education", An Unpublished $\mathrm{PhD}$ dissertation, Northern Arizona University,

Lenartz, A.J (2012) "Establishing Guidelines for the Use of Social Media in Higher Education", In Wankel, Z.A and Wankel, G (eds) Misbehavior Online in Higher Education. Emerald Group Publishing pp.333-353

Lievrouw, L. and Livingstone, S. (2004) A Handbook of New Media, London: LSE Research Publication.

Lister, M. (2002). New Media: A Critical Introduction, London: Routledge. 
Livingstone. S. (2010) "Interactive and Participation on the Internet: Young People's Response to the Civic Sphere" in Dahlgren (Ed.) Young Citizens and New Media: Learning for Democratic Participation, London: Routledge.

Martinez, A and Watman, K.L (2009). Online Social Networking on Campus. New York: Routledge.

McLuhan, M. (1964). Understanding Media: the Extension of Man, Toronto: MCGrow Hill.

McLuhan, M. (1967). The Medium is the Message, Westminster: Random House Publication.

Martinez, A and Watman, K.L (2009). Online Social Networking on Campus. New York: Routledge.

Minacha, S (2009) A Study of the Effective Use of Social Software to Support Student Learning and Engagement, University of Brostol: JISC.

Nigerian National Policy on Education (NPE) (2011 report).

Okebukola, P.A.O (2005) The State of University education in Nigeria, Abuja: NUC.

Oyelaran, et al (2005) "Internet Diffusion in Sub-Sahara Africa: a Cross-Country analysis" in Telecommunication Policy, 29, pp. 507-527.

Waheed ,O (2012) "Assessment of Internet Uses, Practices and Barriers for Professional Development by Agricultural Science Teachers in Lagos State" in Education Research International Vol 1. 